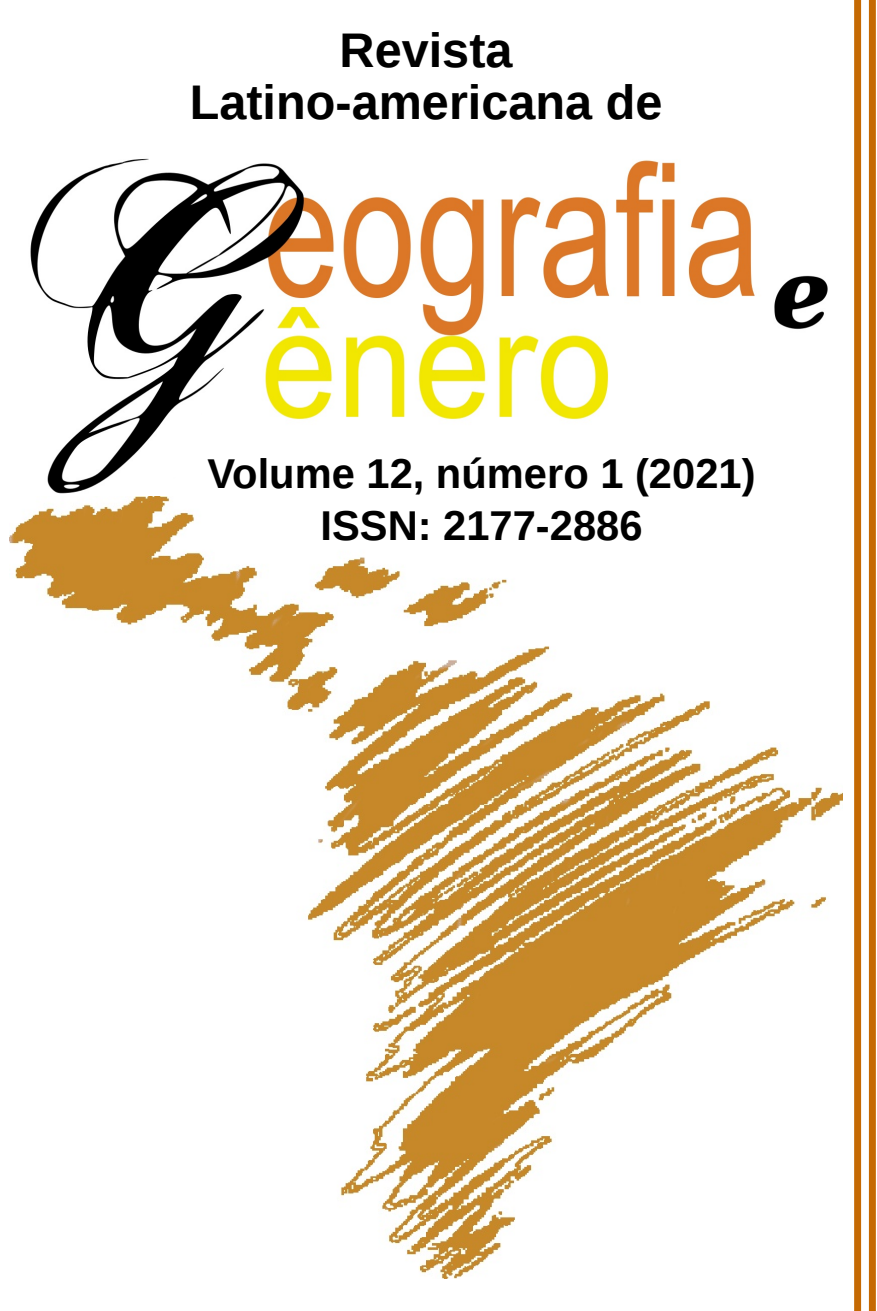

\title{
La Experiencia Espacial del Género, de lo Íntimo a lo Público: Reflexiones desde la Transmasculinidad
}

A Experiência Espacial de Gênero, do Íntimo ao Público: Reflexões da Transmasculinidade

The Spatial Experience of Gender, from the Intimate to the Public: Reflections from Transmasculinity

Balam Sánchez Abúndez

Arquitecto Autónomo - México

arq.balam.san@gmail.com

Como citar este artigo:

ABÚNDEZ, Balam Sánchez. La Experiencia Espacial del Género, de lo Íntimo a lo Público: Reflexiones desde la Transmasculinidad. Revista Latino Americana de Geografia e Gênero, v. 12, n. 1, p. 380-384, 2021. ISSN 2177-2886.

Disponível em:

http://www.revistas2.uepg.br/index.php/rlagg 


\title{
La Experiencia Espacial del Género, de lo Íntimo a lo Público: Reflexiones desde la Transmasculinidad
}

\author{
A Experiência Espacial de Gênero, do Íntimo ao Público: Reflexões da \\ Transmasculinidade
}

\section{The Spatial Experience of Gender, from the Intimate to the Public: Reflections from Transmasculinity}

Me llamo Balam y soy un hombre transgénero de 32 años originario de una pequeña ciudad llamada Cuautla, en el Estado de Morelos, que actualmente reside en la Ciudad de México desempeñándose como arquitecto, principalmente en el ámbito de lo urbano.

Comencé mi transición hace poco más de cuatro años, aunque en aquél momento aún no era consiente de ello. Al principio con cambios que solo buscaban desafiar mi hasta entonces sumisión al mandato de la feminidad: un corte de pelo o el uso de algunas prendas masculinas para sentirme más acorde con mi imagen autopercibida, pero que fueron poco a poco llevándome a querer reflejar esa imagen desde la propia corporalidad, bajo el deseo inescapable de transformarla.

Es así como empecé mi tratamiento hormonal a principios de 2019 que suma, al momento de escribir estas palabras, poco más de quince meses de un camino de cambios físicos y emocionales que se han aparejado con lo que, a mi parecer, ha sido la mayor transformación en mi experiencia de vida: la socio-espacial.

Como arquitecto estoy formado bajo una conciencia espacial, que si bien tiende a mirarlo como materia y material, me ha permitido vislumbrar mi propia transición a la luz de cómo se ha ido transformando mi percepción y la forma de experimentar las múltiples relaciones que se entretejen para conformar el espacio en sus diversas escalas.

Es tan contundente el papel que juega el género en nuestra relación con el mundo que puedo decir el momento preciso en que comencé a ser un hombre para los otros: la primera vez que un desconocido me llamó "joven" en una tienda de electrónica. En ese instante no sólo operó por primera vez mi aspecto para darme la presencia masculina que había deseado, sino que también es cuando recuerdo por primera vez haber ejercido mi rol a través del manejo de mi cuerpo con mi postura, con la modulación de mi voz y con el desenvolvimiento social que se espera de un hombre, al menos en este país.

A partir de ese momento, he sido consciente de la profundidad de las transformaciones en mi experiencia del espacio que han surgido a partir de cómo me perciben los demás y, aún más, de cómo me voy percibiendo a mí mismo, ya que han cambiando no sólo mis rasgos y mi corporalidad, sino también la relación que tengo con mi propio cuerpo, con sus capacidades, sus destrezas y lo que en él es privado a la mirada de los otros.

Es por ello que me gustaría hablar desde dos esferas principales que se han transformado para mí: la personal, de las relaciones primarias y la del espacio social. Todas en las cuales el espacio ha jugado un rol fundamental como agente en proceso de cambio.

Me gustaría comenzar con la esfera de mi primer espacio, el de mi cuerpo. Más de un año en tratamiento hormonal me ha permitido experimentar al día de hoy una serie de cambios tanto fisiológicos como físicos que ya han ido modelando una nueva experiencia de vivir el llamado primer territorio. 
El término de mi ciclo hormonal femenino me ha llevado a dejar atrás algunas restricciones del tiempo-espacio que antes eran determinantes, como lo es planear mis actividades en base a esta necesidad fisiológica.

Mi desarrollo muscular ha ejercido un cambio en la concepción de las cosas que podía o no hacer, desde cosas tan simples como cargar ciertos objetos o abrir frascos en la cocina, hasta mi resistencia física o mi velocidad. Cambios de esta índole me han llevado a modificar los límites que conocía y al hacerlo he transformado mi relación con el mundo, al sentirme, y lo diré en este término, más apto para desenvolverme en él. Llegar a esta sensación no ha sido fácil, ya que si bien ser capaz de ejercer una mayor fuerza o destreza puede resultar positivo, me ha hecho encarar la desventaja física en que estuve toda mi vida tan solo por tener una hormona diferente, situación que me aparece a todas luces injusta y lastimera.

Pero si he de resaltar un hecho que ha sido una transformación radical en la percepción de mi propio cuerpo, es el cambio de lo que en él se concibe como privado. Los cuerpos de hombres y mujeres tienen muy distinto nivel de privacidad y de restricción a los ojos de los demás. Al haberme criado y socializado como mujer por tantos años, enfrentarme a ese cambio de paradigma ha sido un verdadero shock en situaciones que requieren contacto físico, como las revisiones de seguridad ante la portación de armas, por ejemplo, en las que como hombre, además de ser ahora sujeto de sospecha, se requiere un mayor nivel de escrutinio que pasa por los costados del pecho y muy cerca de la entrepierna.

Algo que una mujer aprende desde que tiene conciencia es lo sagrado de su cuerpo, un cuerpo que no se toca ni se muestra y que se debe proteger de cualquier tipo de mirada o roce indiscreto. Un mandato como este es difícil de olvidar, por lo que experimentar por primera vez el ser tocado sin los cuidados que la etiqueta femenina requiere, es una experiencia desagradable e inquietante.

Así mismo la experiencia corporal del deseo cambia entre un cuerpo que se percibe femenino y uno que se percibe masculino. Ahora no siento las miradas que escrudiñan mi pecho pero siento que se me percibe en la dimensión de mi estatura y de mi corpulencia. Me siento medido por otros hombres y al mismo tiempo siento que me encuentro comparándome también con ellos.

Mi nueva corporalidad me exige así repensar mi propio cuerpo, no solo en la medida en que han cambiado aspectos como mi rostro o mi voz, sino más allá de eso a repensarlo en sus límites y sensaciones, en lo que muestra y lo que esconde. Pasar del uso de sostén al de compresor de pecho y ahora incluso a no usar nada, pese a que aún me encuentro lejos de poder llegar a realizarme un procedimiento quirúrgico, ha sido un proceso de autodescubrimiento en que poco a poco he ido cediendo a nuevas formas de experimentar mi desnudez y el cuerpo que se muestra ante los otros.

La experiencia del torso descubierto me resulta aún un enigma, pero siento que me encuentro dando pasos hacia su entendimiento, que pasa por la pérdida paulatina del pudor que asocio con la idea del pecho femenino como objeto sagrado y, sobre todo, como objeto de deseo.

Esto me lleva hacia el segundo espacio en que he experimentado profundas transformaciones, que es mi espacio social, particularmente en el ámbito en

Balam Sánchez Abúndez 
Los últimos meses de mi vida han sido una ardua labor de reinterpretar códigos. A partir del momento en que se me empezó a percibir como un hombre, comencé a notar cómo algunas de las más férreas sensaciones que hasta entonces había experimentado en el espacio público comenzaban a transformarse, como lo es la percepción de la seguridad y de la pertenencia.

Como mujer crecí bajo un sentimiento de vulnerabilidad que viene aparejado al cuerpo y que se manifiesta en cómo nos desenvolvemos en el espacio a través de estrategias para nuestro autocuidado, como lo es la elección de rutas, de horarios, de vestimenta y de un estado permanente de alerta ante las miradas y los encuentros, más aún si éstos se dan con hombres en grupo, lo que puede llegar a causar un gran estrés si se trata de condiciones en que no se cuenta con posible ayuda.

Estas sensaciones del cuerpo en el espacio se graban a fuego en el subconsciente de las mujeres, condicionando sus decisiones en lo público y en lo privado, en sus relaciones personales y en los encuentros fortuitos en la ciudad, por lo que no resulta fácil transformar años de este condicionamiento en un periodo de apenas unos meses, como es el caso de lo que lleva mi transición.

Es por ello que resulta sorprendente la manera en que poco a poco el cuerpo va desprendiéndose de esas ataduras y se va volviendo parte del espacio de la ciudad y de los otros de una forma más orgánica. No he llegado al punto de olvidar el estrés que podría causarme el transitar en una calle oscura o en soledad, sin embargo me percibo menos vulnerable que antes, o al menos un poco más invisible, como si ahora fuera parte de los seres que son propios de ese espacio y no de los que están allí irrumpiéndolo, llamando la atención.

Es muy fuerte la experiencia de apropiarse de un espacio por primera vez. Hasta hace unos cuantos meses había sido incapaz de plantarme en la zona de ejercitadores de mi parque local. Era un espacio exclusivo de los hombres, quienes se ejercitan allí en grupos de amigos que traen sus pesas y aparatos y que lo hacen muchas veces sin camisa, dado que la calistenia que practican pasa por ser también una demostración de fuerza y habilidad.

Las mujeres también asisten a este parque para hacer caminata o ejercicio pero se mantienen siempre fuera de este espacio, a sus alrededores, lejos de las miradas de aquéllos a quienes perciben probablemente como potenciales agresores.

En mi proceso de transición el ejercicio físico ha sido un elemento determinante en la búsqueda de un cuerpo más masculino, ya que poseo de nacimiento un cuerpo que podría ser considerado como "latino", de caderas prominentes y tendencia a la acumulación de grasa en las zonas que dan la forma curvilínea. Es por ello que incursionar en este espacio se volvió necesario, pese a que al principio me sentía completamente fuera de lugar.

Con el tiempo y ante un mayor progreso en mi apariencia, el tomar por asalto las barras se ha vuelto algo más cotidiano, en donde opera la competencia más que el miedo a la agresión. Soy ahora uno más de aquellos que concurren allí a ejercitarse y a pasar un momento, descubriendo que además se encuentran ensimismados, sin mirar o pretender abordar a las mujeres de los alrededores. 


\section{desde la Transmasculinidad}

La conquista de un espacio hasta ahora inaccesible para mí, ha sido una de las mayores demostraciones de cómo el género se encuentra inscrito en cada uno de los lugares en que discurrimos y en cada una de las relaciones que se entretejen a través de nuestra presencia en el espacio.

En cada momento somos sujetos activos construyéndonos para los demás aunque en apariencia no estemos realizando ninguna acción. Nuestra sola existencia requiere de complejas operaciones de reconocimiento e inteligibilidad que le dan cierta estructura a nuestra presencia, modificando a su vez el espacio en que nos encontramos interactuando.

Es cierto que, como explica Doreen Massey, el espacio es un proceso y como tal se encuentra en constante transformación, nunca acabado. Mi propia experiencia, desde la esfera íntima hasta la social, me permite constatar que, tanto mi percepción del espacio como mi impronta en el mismo, han cambiado radicalmente al entrar en la ecuación la variable del género, de mi propio género.

Aquéllos que transitamos nos permitimos explorar un mundo que de otra forma nos sería desconocido, apenas revelado entre el telón de los prejuicios y el tabú. Al hacerlo, no solo ponemos en duda las barreras que separan a los géneros, rígidas en apariencia, llenas de contradicciones, sino que también ponemos de manifiesto los puentes que los hermanan, donde nuestro devenir, con sus propias características y revelaciones, se convierte para ellos en un eslabón.

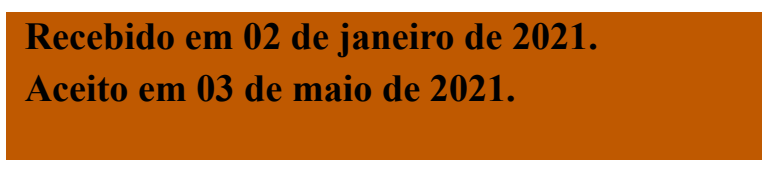

